\title{
Glutathione peroxidase in bovine semen
}

\author{
D. V. Brown, P. L. Senger, S. L. Stone, J. A. Froseth and W. C. Becker \\ Department of Animal Sciences, Washington State University, \\ Pullman, Washington 99163, U.S.A.
}

The roles of selenium (Se) and glutathione peroxidase in reproductive function are poorly understood, but it is possible that they may be important for normal reproduction in the male. In rats fed a Se-deficient diet, the testes accumulated and retained more ${ }^{75} \mathrm{Se}$ than did other tissues 1 week after injection (Brown \& Burk, 1972; Burk, Brown, Seely \& Scaief, 1972). Autoradiographic studies (Brown \& Burk, 1972) of spermatozoa recovered from rat epididymides have shown that ${ }^{75} \mathrm{Se}$ is associated with the midpiece of the spermatozoon. Gould (1970) has suggested that ${ }^{75} \mathrm{Se}$ is probably incorporated into late spermatocytes or early spermatids in the rat. Rotruck et al. (1973) demonstrated that $\mathrm{Se}$ is a component of glutathione peroxidase, an enzyme which has been reported to exist in $\mathrm{dog}$, goat, ram and human semen $(\mathrm{Li}, 1975)$. The objectives of the present study were to determine whether glutathione peroxidase is present in ejaculated bovine semen and the relationship of the enzyme levels to sperm concentration and ejaculate volume.

The first 2 successive ejaculates from each of 10 mature dairy bulls were collected by means of an artificial vagina. Immediately after collection and determination of ejaculate volume, sperm concentration and percentage of motile spermatozoa, $0.4 \mathrm{ml}$ whole semen was packaged in $1-\mathrm{ml}$ glass ampoules and frozen in $\mathrm{N}_{2}$ vapour until assayed for glutathione peroxidase. The percentage of motile spermatozoa ranged from 40 to $70 \%$ with a mean motility for all ejaculates of $63 \%$. At the time of assay, samples were thawed at $37^{\circ} \mathrm{C}$ for approximately $4 \mathrm{~min}$, and 1 part semen was diluted with 99 parts glass-distilled water. The diluted samples were assayed for glutathione peroxidase activity according to procedure II of Mills (1959) as modified by Hafeman, Sunde \& Hoekstra (1974). A blank (with glass-distilled water substituted for the semen sample) was incubated simultaneously with the semen samples because nonenzymatic oxidation of reduced glutathione (GSH) by $\mathrm{H}_{2} \mathrm{O}_{2}$ occurs during incubation (Hafeman et al., 1974). The enzymatic and nonenzymatic reactions proceeded at rates directly proportional to the glutathione concentration because a plot of log [GSH] against reaction time was linear with and without addition of enzyme source. An enzyme unit was arbitrarily defined as a decrease in the log concentration of $0.001 \mathrm{~mol} \mathrm{GSH} / \mathrm{litre} / \mathrm{min}$ after the average decrease in log [GSH] of the nonenzymatic reaction was subtracted (Hafeman et al., 1974). Each ejaculate was assayed in duplicate. The coefficient of variation among duplicates in this study was $4.7 \%$.

For all 20 ejaculates, the concentration of glutathione peroxidase ranged from 1978 to 5100 units/ ml semen with a mean ( \pm S.D.) for all ejaculates of $3197 \pm 830$. An analysis of variance showed that the variation $(P<0.01)$ in the enzyme concentration was associated with bulls and ejaculates within bulls. There was no consistent relationship between glutathione peroxidase levels in the 1st and 2nd ejaculates and the levels were not correlated with changes in sperm concentration among 19 ejaculates (Text-fig. 1a). However, a positive correlation $(r=0.70, P<0.01)$ existed between the enzyme activity/ejaculate and ejaculate volume (Text-fig. $1 \mathrm{~b}$ ). Since ejaculate volume is a function of sperm number and seminal plasma volume, the positive correlation of glutathione peroxidase levels with ejaculate volume but not sperm number suggests that this enzyme is high in seminal plasma and low in spermatozoa in ejaculated bovine semen.

The physiological role of glutathione peroxidase in semen is presently unknown. However, glutathione peroxidase has been shown to protect the plasma membrane of the erythrocyte from oxidative damage (Mills \& Randall, 1958; Cohen \& Hochstein, 1963; Combs, Noguchi \& Scott, 1975). The enzyme catalyses the oxidation of $\mathrm{GSH}$ and the reduction of $\mathrm{H}_{2} \mathrm{O}_{2}$ to $\mathrm{H}_{2} \mathrm{O}$. The oxidized glutathione disulphide thus formed is reconverted to reduced glutathione by glutathione reductase. This glutathione cycle has been shown by Kosower, Marikovsky, Wertheim \& Danon (1971) to be an effective intracellular defence mechanism against oxidant stresses in erythrocytes and may serve a similar function in the lung (Chow \& Tappel, 1972) and liver (Flohé \& Zimmerman, 1970). 

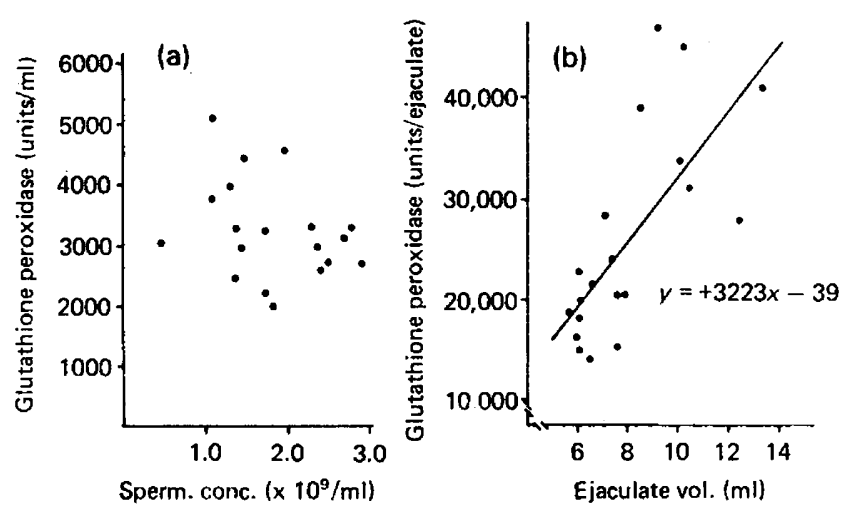

Text-fig. 1. Scatter plots of the amounts of glutathione peroxidase against (a) sperm concentration and (b) ejaculate volume. See text for definition of enzyme units.

Mammalian semen does not contain catalase (Mann, 1964) and glutathione peroxidase may therefore reduce $\mathrm{H}_{2} \mathrm{O}_{2}$ to $\mathrm{H}_{2} \mathrm{O}$ and play a critical role in the prevention of oxidative damage to spermatozoa.

Glutathione peroxidase also functions in the biosynthetic pathway of prostaglandins (Nugteren \& Hazelhof, 1973) and its presence in semen may be related to prostaglandin synthesis by the accessory sex glands.

We thank Mr Louis Mikota and Mr Mike Jungers of Allwest Breeders/Select Sires, Burlington, Washington 98233, for their co-operation and for collecting semen for this study. This is Scientific Paper No. 4678 of the College of Agriculture Research Center, Washington State University, Project 0237.

\section{References}

Brown, D.G. \& BuRK, R.F. (1972) Selenium retention in tissues and sperm of rats fed a torula yeast diet. J. Nutr. 103, 102-108.

Burk, R.F., Brown, D.G., Seely, R.J. \& Scaief, C.C. (1972) Influence of dietary and injected selenium on whole-body retention, route of excretion, and tissue retention of ${ }^{75} \mathrm{SeO}_{3}{ }^{2-}$ in the rat. $J$. Nutr. 102, 10491056.

Chow, C. \& Tappel, A.L. (1972) An enzymatic protective mechanism against lipid peroxidation damage to lungs of ozone-exposed rats. Lipids 7, 518524.

Cohen, G. \& Hochstein, P. (1963) Glutathione peroxidase: the primary agent for the elimination of hydrogen peroxide in erythrocytes. Biochemistry, N.Y. 2 , $1420-1428$.

Combs, G.F., Noguchi, T. \& ScotT, M.L. (1975) Mechanisms of action of selenium and vitamin $E$ in protection of biological membranes. Fedn Proc. Fedn Am. Socs exp. Biol. 34, 2090-2095.

Flohé, L. \& Zimmerman, R. (1970) The role of GSH peroxidase in protecting the membrane of rat liver mitochondria. Biochim. Biophys. Acta 223, 210-213.

Gould, T.C. (1970) Incorporation of minerals in spermatogenic pathway. Morph. Aspects Andrology 1, 56-60.
Hafeman, D.G., Sunde, R.A. \& Hoekstra, W.G. (1974) Effect of dietary selenium on erythrocyte and liver glutathione peroxidase in the rat. $J$. Nutr. 104, 580587.

Kosower, N.S., Marikovsky, Y., Wertheim, B. \& DanoN, D. (1971) Glutathione oxidation and biophysical aspects of injury to human erythrocytes. J. Lab. clin. Med. 78, 533-545.

LI, T. (1975) The glutathione and thiol content of mammalian spermatozoa and seminal plasma. Biol. Reprod. 12, 641-646.

Mann, T. (1964) The Biochemistry of Semen and of the Male Reproductive Tract. Methuen, London.

MiLLs, G.C. (1959) The purification and properties of glutathione peroxidase of erythrocytes.J. biol. Chem. 234, 502-506.

Mills, G.C. \& Randall, H.P. (1958) The protection of hemoglobin from oxidative breakdown in the intact erythrocyte. J. biol. Chem. 232, 589-598.

Nugteren, D.H. \& Hazelhof, E. (1973) Isolation and properties of intermediates in prostaglandin biosynthesis. Biochim. Biophys. Acta 326, 448-461.

Rotruck, J.T., Pope, A.L., Ganther, H.E. Swanson, A.B., Hafeman, D.G. \& Hoekstra, W.G. (1973) Selenium: biochemical role as a component of glutathione peroxidase. Science, N.Y. 179, 588. 